\title{
Correction to: Socioeconomic inequalities in survival of children with acute lymphoblastic leukemia insured by social security in Mexico: a study of the 2007- 2009 cohorts
}

\author{
Angélica Castro-Ríos ${ }^{1 *}$, Hortensia Reyes-Morales², Blanca E. Pelcastre-Villafuerte², Mario E. Rendón-Macías ${ }^{1,3}$ \\ and Arturo Fajardo-Gutiérrez ${ }^{1}$
}

\section{Correction to: International Journal for Equity in Health} https://doi.org/10.1186/s12939-019-0940-3

Following publication of the original article [1], the author reported her name has been erroneously spelled as Blanca E. Pelcastre. The full name is Blanca E. Pelcastre-Villafuerte.

It has been corrected in the original article as well.

The publisher apologizes for any inconvenience caused by this error.

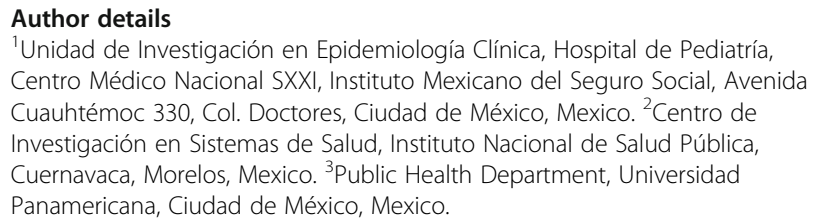

Received: 29 March 2019 Accepted: 29 March 2019

Published online: 08 April 2019

\section{Reference}

1. Castro-Ríos A, et al. Socioeconomic inequalities in survival of children with acute lymphoblastic leukemia insured by social security in Mexico: a study of the 2007-2009 cohorts international journal for equity in health, vol. 18; 2019. p. 40. https://doi.org/10.1186/s12939-019-0940-3.

\footnotetext{
* Correspondence: angelica.castror@imss.gob.mx; castrorios.a@gmail.com 'Unidad de Investigación en Epidemiología Clínica, Hospital de Pediatría, Centro Médico Nacional SXXI, Instituto Mexicano del Seguro Social, Avenida Cuauhtémoc 330, Col. Doctores, Ciudad de México, Mexico

Full list of author information is available at the end of the article
} 